\title{
Del tiempo de la imagen del mundo a la época de la transparencia: una reflexión sobre la experiencia del tiempo en la filosofía contemporánea
}

\author{
From the Time of World-Image to the Age of Transparency: \\ a Reflection on the Experience of Time \\ in Contemporany Philosophy
}

\author{
ALBA JIMÉNEZ RoDRÍGUEZ* \\ Universidad Complutense de Madrid
}

RESUMEN. El presente trabajo tiene como objetivo dar cuenta del carácter ambivalente de los conceptos de transparencia y aceleración como claves de comprensión de las transformaciones de las concepciones del tiempo de la modernidad a la postmodernidad. Para arrojar luz sobre esta doble valencia se apelará a la diferencia entre una aceleración centrífuga propia de la modernidad, cuya estructura temporal se articula como aproximación asintótica al foco de luz que la orienta, frente a una aceleración centrípeta donde la transparencia es tan perfecta que, sin fondos opacos de retracción, ni centro de gravedad que ordene el decurso temporal, entrega todo a la visibilidad quedando el concepto de libertad fatalmente identificado con la autocoacción.

Palabras clave: aceleración; transparencia; tiempo; mundaneidad; narratividad; psicopolítica; coacción; modernidad.
ABSTRACT. This contribution aims to highlight the ambivalent condition of the concepts of transparency and acceleration, considered as key concepts for the understanding of the changes experienced by the conceptions of time from Modernity to Postmodernity. In order to enlight this double value, we will show the difference between a centrifugal acceleration, due to modernity, tied to modernity, which time structure is articulated as an asymptotical approach to the focal point toward it is oriented, and a centripetal acceleration, where the transparency is so perfect that in absence of both bottoms of retraction and a center of gravity providing an order to the time sequence, it expounds all to the visibility, as the concept of freedom unfortunately remains linked to the selfcoercion.

Key words: Acceleration; Transparency; Time; Worldliness; Narrativity; Psychopolitics; Coercion; Modernity.

\footnotetext{
*albjim04@ucm.es. ORCID iD https://orcid.org/0000-0003-4381-3434.

Copyright: (C) 2018 CSIC. Este es un artículo de acceso abierto distribuido bajo los términos de la licencia de uso y distribución Creative Commons Reconocimiento 4.0 Internacional (CC BY 4.0).
} 


\section{LA ACELERACIÓN COMO CLAVE DE COMPRENSIÓN DE LA EXPERIENCIA POST(MODERNA) DEL TIEMPO}

El tiempo al cual se le imputa el crimen perfecto, a saber, el asesinato de la realidad $^{1}$, la desaparición del sujeto ${ }^{2}$, el fin de la temporalidad ${ }^{3}$, el ocaso de la Historia ${ }^{4}$ o el agotamiento de los grandes metarrelatos ${ }^{5}$ ha de suspenderse en la siguiente encrucijada: la aceleración, que parece tener como su condición de posibilidad más inmediata la concepción lineal de la historia propia de la Modernidad, se presenta sin embargo como un rasgo inequívocamente característico de la época que se define a sí misma como rebasamiento o cancelación de dicha Modernidad. ${ }^{6}$ De un lado, la aceleración, como magnitud vectorial, requiere por definición una dirección o sentido y un cambio de velocidad respecto de otra anterior; como si dijésemos: en el ahora presente y con relación a un ahora pasado, tardamos menos en aproximarnos a un determinado telos que ordena, articula y rotura el camino a recorrer de antemano. Sin embargo, como se ha señalado, la postmodernidad y la concepción heterárquica de la realidad que alberga, parece por definición claudicar ante toda forma de narración que implique partir de un centro de sentido cerrado y autofundamentado que otorgue su lugar a otras manifestaciones simbólicas, prácticas de verdad, instituciones, cosmovisiones, etc.

Bien podría pretenderse escapar a esta paradoja reivindicando el carácter falaz de equiparar dos tiempos de naturaleza diversa: de lo que se habla en un caso, podría argumentarse, es del agotamiento de la duración, de un tiempo intensivo y ordenado que, tras su resquebrajamiento, habría dejado tras de sí una multitud de tiempos extensivos y seriales. Pero entonces cabría seguir preguntando si la aceleración es un fenómeno que no puede concebirse sin presuponer una estructura teleológica o, bien al contrario, es una consecuencia necesaria de esa hendíadis espacio-temporal, herencia de lo que Heidegger o

${ }^{1}$ Baudrillard, J.: El crimen perfecto, trad. de Joaquín Jordá, Anagrama, Barcelona, 2000.

${ }^{2}$ Bürger, P. y Bürger, Ch.: La desaparición del sujeto: una historia de la subjetividad de Montaigne a Blanchot, trad. de A. González Ruiz, Akal, 2001.

${ }^{3}$ Jameson, F.: "The end of Temporality" en: Critical Inquiry, The University of Chicago Press, Vol. 29, nº , pp. 695-718. Jameson, F y Sánchez Usanos, D.: Reflexiones sobre la postmodernidad. Una conversación de F. Jameson con D. Sánchez Usanos, Abada, Madrid, 2012.

${ }^{4}$ Fukuyama, F.: El fin de la historia y el último hombre, trad. de P. Elías, Planeta, Barcelona, 1992.

${ }^{5}$ Lyotard, J.-F.: La condición postmoderna. Informe sobre el saber, trad. de M. Antolín Rato, Cátedra, Madrid, 1987.

${ }^{6}$ Vattimo, G.: La sociedad de la transparencia, trad. e introducción de Teresa Oñate, Paidós, Barcelona, 1990. 
Bergson llamaron la concepción vulgar del tiempo, desde la que los acontecimientos se suman homogéneamente partes extra partes y no necesariamente siguiendo una trayectoria orientada y reconocible ${ }^{7}$. La pregunta a la que se trata de dar respuesta es por tanto por qué la aceleración que parecía encontrar su justificación teórica en cierta estructura temporal propia de la modernidad ha vehiculado tantas interpretaciones de la experiencia de lo que se ha dado en llamar postmodernidad, entendida precisamente como una quiebra de la estructura narratológica propia de los modernos y, si sería oportuno en ese sentido hablar de dos tipos diferenciados de aceleración. ${ }^{8}$

Por lo demás, conviene señalar que tampoco podría afirmarse sin ciertas cautelas que la mencionada concepción lineal o espacializada del tiempo es un rasgo inequívocamente propio de lo moderno. Sino que, más bien, la caracterización del tiempo como escenario del mundo o su subordinación a aquello que pasa en él ha sido también tradicionalmente puesto en relación con una experiencia temporal todavía anterior. Así, por ejemplo, la descripción física del tiempo de Aristóteles, de forma paradigmática, permanece inscrita en un marco donde sí tiene lugar una clara dependencia estructural entre éste y el espacio o el movimiento. $\mathrm{Y}$, a diferencia de la concepción cíclica del tiempo de los antiguos, se dice que el tiempo de los modernos es un tiempo "descurvado", donde los límites ya no indican operaciones de delimitación, digamos, separación o inscripción de hitos y secuencias homogéneos sino, más bien, el término (en sentido matemático) hacia el cual las cosas tienden. ${ }^{9}$ Esta es la razón de que la ilustrada aproximación progresiva del género humano hacia lo mejor tenga un carácter asintótico.

Que la aceleración implica la presuposición de la existencia de un término, queda ya suficientemente argumentado en la obra de Koselleck. ${ }^{10} \mathrm{Al}$ analizar la diferencia entre la contracción del tiempo en el horizonte escatológico cristiano y la producida en el marco de la concepción moderna regida por la idea de progreso como consecuencia del acortamiento que la aceleración conlleva en los procesos temporales, resuelve que la presunción de un télos al que la historia debe aproximarse es el rasgo determinante que ambos planteamientos tienen en común. Siguiendo a Koselleck, podría ahora formularse la cuestión en los siguientes términos: ¿por qué la época que se define a sí misma como re-

\footnotetext{
${ }^{7}$ Heidegger: Prolegómenos para una historia del concepto de tiempo, trad. de J. Aspiunza, Alianza, Madrid, 2006.

${ }^{8}$ Sobre el concepto de Modernidad hemos seguido en sus líneas generales el artículo de R. Koselleck: "Modernidad" en: Futuro, pasado. Para una semántica de los tiempos históricos, Paidos, Barcelona, 1993.

${ }_{9}^{9}$ Deleuze, Kant y el tiempo, trad. de Equipo Editorial Cactus, Cactus, Buenos Aires, 2008.

${ }^{10}$ Koselleck, R.: Aceleración, prognosis y secularización, trad. introducción y notas de F. Oncina, Pre-textos, Valencia, 2003.
} 
basamiento de la Modernidad a través de la cancelación de algunos de sus supuestos fundamentales se define a sí misma a partir de un concepto como el de aceleración cuya condición de posibilidad parece precisamente cifrarse en la mundanización propia de la edad moderna?

Para que el tiempo se independice de los ritmos y los ciclos de la naturaleza, o, más claramente, para que el tiempo ya no sea más la relación de Dios con el Mundo y comience a darse a sí mismo sus propias leyes inmanentes es preciso que la relación vertical entre el más allá y el más acá se troque en una relación lineal entre pasado y futuro. Ahora bien, si la manera en la que dicha estructura es la condición de posibilidad del tipo de distensión acelerada o aceleración con el que se describen las sociedades postmodernas o adopta una naturaleza diferente es algo que todavía es preciso responder.

\section{FINITUD Y ACELERACIÓN}

En lo que sigue se tratará de analizar el rendimiento crítico que la lectura foucaultiana de Kant puede ofrecer para pensar algunos lugares comunes de la modernidad filosófica y de su pretendida superación con el objeto más específico de tratar de responder desde esta clave a la pregunta por el vínculo entre la aceleración y la llamada sociedad de la transparencia y, ulteriormente, ofrecer una tentativa de respuesta a la ambivalencia señalada por la cual, la aceleración parece simultáneamente dar cuenta tanto de cierta forma de temporalidad característica de la Modernidad, como de su propia cancelación. Para abordar esta cuestión se atenderá brevemente a dos cuestiones ligadas al pensamiento de $\mathrm{M}$. Foucault en el marco de su crítica a la modernidad: la aplicación de sus tesis acerca del cuidado de sí a las prácticas de subjetividad involucradas en el creciente uso de las redes sociales y la puesta en común de sus propuestas sobre el panoptismo de Vigilar y Castigar y de los cursos de 1979 sobre El Nacimiento de la biopolítica con el concepto de psicopolítica de Han que, a nuestro juicio, trata de superar con poco acierto los presupuestos foucaultianos ${ }^{11}$.

Tomamos al respecto como punto de partida su interpretación del texto kantiano Respuesta a la pregunta: ¿qué es la Ilustración? y el comentario y traducción de la Antropología en sentido pragmático de Kant que Foucault escribe como trabajo complementario a su Historia de la Locura donde formula su tesis fundamental acerca del desplazamiento operado en el modo de concebir la finitud como piedra de toque del proyecto filosófico moderno. ${ }^{12}$ En la traduc-

${ }^{11}$ Han, Byung-Chul: La sociedad de la transparencia, Barcelona, Herder, 2013.

${ }^{12}$ Foucault, M.: Kant, I.Anthropologie d'un point de vue pragmatique. Précédé de Introduction à l'anthropologie. Librairie Philosophique J. Vrin, Paris, 2008, p. 8. 
ción que Foucault realiza de la Antropología kantiana, sostiene la tesis de que el pensamiento clásico vendría caracterizado por el carácter vicario de lo finito respecto de la infinitud de la que participa mientas que, en principio, la reflexión moderna cifra su pensamiento de lo finito desde la finitud misma. Así, cuando Alain Badiou le pregunta a Foucault en 1965 por el estatuto de la psicología, éste señala cómo antes de Kant, los filósofos habían cuestionado las representaciones y el conocimiento de sus objetos desde las conclusiones invariables extraídas de la física o las matemáticas, mientras que en el caso del filósofo regiomontano, se produce un giro radical según el cual desaparece lo infinito en favor de una consideración inmanente de lo finito por lo finito mismo. ${ }^{13}$ Esta conclusión se torna algo difícil de comprender, si pensamos en el carácter pragmático de la antropología por un lado, el papel otorgado a las matemáticas por su vínculo con el modo de proceder del entendimiento arquetípico establecido en el escrito de habilitación de 1770 y en la división entre lo finito y lo infinito que articula todo el proyecto crítico kantiano desde su teoría del conocimiento hasta los postulados de la filosofía moral o los fundamentos del derecho natural y la filosofía de la historia. O, en la línea de la lectura habermasiana, si pensamos en el reconocimiento de la conversión kantiana de las "limitaciones de una capacidad cognoscitiva finita en condiciones trascendentales de un conocimiento que progresa hasta el infinito". ${ }^{14}$

Parece indudable, en cualquier caso, que puede trazarse una línea de continuidad entre el acento puesto por Foucault en la consideración de la finitud desde la finitud misma y la aceleración, entendida como un rasgo propio de la sociedad contemporánea. La paradójica correlación invariante entre la aceleración y el decremento de tiempo libre que consigna el ser finito como posibilidad, notablemente aceptada en el campo de la sociología, se presenta pues como uno de los frutos más visibles de nuestra condición presente, que alumbra la posibilidad de pensar otro modo de concebir la experiencia temporal. Si la finitud ya no cuenta con un horizonte supraempírico desde el cual medirse y orientarse, la aceleración de su horizonte temporal no puede significar sino

\footnotetext{
${ }^{13} \mathrm{O}$, cuando aborda los semitrascendentales trabajo, vida y lenguaje: "la positividad de la economía se ubica en este hueco antropológico. El homo oeconomicus no es aquel que se representa sus propias necesidades y los objetos capaces de satisfacerlas; es el que pasa, pierde y usa su vida, tratando de escapar a la inminencia de la muerte: es un ser finito. Y así como a partir de Kant la cuestión de la finitud se hizo más fundamental que el análisis de las representaciones (este sólo podía ser derivado en relación a aquella), a partir de Ricardo, la economía descansa, de manera más o menos explícita, en una antropología que tiende a señalar formas concretas a la finitud". Foucault, M.: Las palabras y las cosas, una arqueología de las ciencias humanas, trad. de E. C. Frost, S. XXI, España, 1988, p. 252.

${ }^{14}$ Habermas, J.: EL discurso filosófico de la modernidad, M. Jiménez Redondo (trad.), Taurus, Madrid, 1989, p. 37.
} 
un incremento lineal de velocidad que nada tiene que ver con la aceleración centrífuga producida por una fuerza real o un verdadero punto de gravedad externo.

\section{TRANSPARENCIA Y NARRACIÓN}

Los textos del filósofo coreano Byung Chul-Han y, sobre todo, algunos de los ecos heideggerianos que resuenan en ellos, pueden resultar como explicaremos a continuación un contexto idóneo para analizar tanto las contradicciones y subrepciones que dan lugar a la paradoja formulada sobre la aceleración, como la puesta en funcionamiento de la misma, con todo su rendimiento y poder explicativo. En esta línea, se tratará de visibilizar la distinción entre los dos tipos de aceleración mencionados y su posible relevancia. En los trabajos de Han la cuestión de la aceleración viene ligada a dos matrices de problemas cuya raíz se encuentra en un análisis de las estructuras temporales de la modernidad tardía. En primer lugar, la caída del modelo de pensamiento narratológico, ligada a la perdida de instancias suprahistóricas y trascendentes que abocarán en lo que Lanceros había diagnosticado antes, de nuevo como característica esencial a la modernidad, como la reducción del enigma a la incógnita. ${ }^{15}$ En segundo lugar, su presentación de lo que se dio en llamar como sociedad de la transparencia y su interpretación de la sustitución del paradigma biopolítico por el paradigma psicopolítico. Trataremos en lo que sigue de dar cuenta de ambos núcleos de problemas así como de su respectiva relación con la cuestión del tiempo para concluir proponiendo unas breves consideraciones sobre la distinción enunciada a propósito de los tipos de aceleración.

Respecto de la pérdida de narratividad, pueden trasladarse a nuestro contexto algunas de las conclusiones fundamentales a las que Paul Ricoeur llega en ese diálogo triple entre la fenomenología, la historiografía y la crítica literaria a propósito de la definición de la trama narrativa como síntesis de lo heterogéneo. ${ }^{16}$ En la Poética de Aristóteles, texto que sirve a Ricoeur para analizar el fenómeno de la construcción de la trama, los fenómenos de la pericia, la agnición o el lance patético se presentan precisamente como modalidades del cambio o cambios de estado. El cambio del sentido de la acción o el paso de la ignorancia al conocimiento o del no-ser al ser implican ya de suyo la existencia de un antes y un después. Un antes y un después que, sometidos a la categoría de causalidad, implican que no son en modo alguno reversibles y que deben por tanto seguir ese orden necesariamente. Además, el horizonte planteado por Ricoeur tiene la virtud de anticipar algunas conclusiones sobre el tiempo que rescatan el papel de la imaginación y el rendimiento que la doctrina kantiana del

${ }^{15}$ Lanceros, P.: La modernidad cansada y otras fatigas, Biblioteca Nueva, Madrid, 2006, p. 97.

${ }^{16}$ Ricoeur P.: Tiempo y narración I. Configuración del tiempo en el relato histórico, trad. de A. Neira, S.XXI Editores, Argentina, 2004, p. 31. 
esquematismo trascendental pueda tener para explicar la transformación de la estructura temporal que puede dar lugar a dos tipos diferenciados de aceleración.

En uno y otro caso [la metáfora y la trama], la innovación semántica puede relacionarse con la imaginación creadora y, más exactamente, con el esquematismo que es su matriz significante (...) La imaginación creadora que actúa en el proceso metafórico es así capaz de producir nuevas especies lógicas por asimilación predicativa, a pesar de la resistencia de las categorizaciones usuales del lenguaje ${ }^{17}$.

Pues bien, la trama de la narración es comparable a esta asimilación predicativa: ella "toma juntos" e integra en una historia total y completa los acontecimientos múltiples y dispersos, y así esquematiza la significación inteligible que se atribuye a la narración tomada como un todo.

Este «tomar juntos» de los acontecimientos fragmentarios y dispersos y la modificación del espacio lógico que conlleva es muy diferente del tipo de reunión o recolección que se produce en determinados espacios virtuales que pueden funcionar como metáfora de las transformaciones que acompañan a las presentes concepciones del tiempo. Redes sociales como Facebook se anuncian como lugares que "te ayudan a comunicarte" e incluso como proveedores de un timeline en el que la propia actividad de la plataforma se entreteje con los hitos seleccionados, normalmente imágenes, que tratan de construir una historia de vida. La comunicabilidad definida por Ricoeur como una forma de mediación entre hombres frente a la referencialidad y la comprensión de sí, a través de las cuales nos relacionamos respectivamente con el mundo y con nosotros mismos parece sin embargo en el marco de este espacio desprovisto de toda eficacia narrativa. En primer lugar porque narrar significa de algún modo empezar por el final. Pero Facebook funciona como un depósito o un almacén, en ningún caso como un teatro o como un lugar de transmisión de sedimentos efectivamente susceptibles de ser reactivados y cuyo discurrir pueda reconstruirse de principio a fin. En la medida en que carece de todo foco articulador de sentido y de toda mediación, sus posibilidades de comunicar y de contar historias son por definición muy limitadas. La aporía presentada por Ricoeur entre vivir o narrar no tiene si quiera lugar donde propiamente nada pasa y nada permanece. Así, corrigiendo a Sartre, habría que decir: ni se vive, ni se narra. La narración implica un exceso respecto del acopio discreto de hitos que la soportan: la sucesión fragmentaria de posts de Facebook se configura sin embargo como una serie defectuosa donde la posibilidad infinita de acumulación encubre una serie igualmente infinita de hitos que se sustraen a la representación.

${ }^{17}$ Ibíd. pág. 32. La reflexión sobre el esquematismo narrativo es desarrollada ulteriormente en el Capítulo Tiempo y Narración. La triple mímesis. Cfr.: 136. 
La mediación necesaria para la comprensión o el cuidado de sí también parecen estar vedados. Los intelectuales y formadores de opinión, haciendo uso de su sana razón transparente y pública, nos ilustran a la gente de a pie con sus hypomnémata, sus reflexiones breves y sus aleccionadoras colecciones de citas que, con un poco de suerte podrán desfilar después convenientemente en alguna sección de prensa generalista. Lo cierto es que dichos registros de notas rara vez generan un genuino espacio de relectura, diálogo o reflexión pues ni se vuelve nunca sobre ellos ni se produce una ulterior recolección de esos fragmentos dispersos que aparecen amalgamados más bien a la manera de un collage. No puede tampoco por tanto constituirse como ejercicio de escritura. Foucault recoge el concepto de stultia de Séneca para ejemplificar el modo de dispersión contrario a la escritura:

«La escritura como manera de recoger la lectura hecha y de recogerse en ella es un ejercicio de razón que se opone al gran defecto de la stultitia que la lectura infinita corre el riesgo de favorecer. La stultitia se define por la agitación del espíritu, la inestabilidad de la atención, el cambio de las opiniones y de las voluntades y, por consiguiente, por la fragilidad ante cuantos acontecimientos se puedan producir; se caracteriza también por el hecho de que vuelve el espíritu hacia el porvenir, lo torna curioso de novedades y le impide darse un punto fijo en la posesión de una verdad adquirida.» ${ }^{18}$

Tampoco representan ejemplos para la vida práctica ni se someten a verdaderos ejercicios de resistencia; el "me gusta" ataja cualquier momento de negatividad y allana toda posibilidad de demorarse críticamente en lo dicho. Incluso el carácter absolutamente indeleble de lo dicho imposibilita la reactivación del decir o la posibilidad de fijar un pasado al cual retirarse. Los usuarios -Ricoeur subrayaba que el sentido de la intriga se da en la intersección del mundo del relato con el mundo del lector- se comportan más como consumidores que como lectores, hecho que tiene por lo demás una clara consecuencia política: no es preciso ni cambiar el estado de cosas -es suficiente con que la opinión, muy crítica, eso sí, fluya ininterrumpidamente para recibir el aplauso de los clientes, los seguidores, los alumnos o los otros miembros del partido- ni generar compromisos morales: en la vida privada o en el ámbito laborar, todo lo que es útil está permitido. Bajo este ingrávido consenso manufacturado no es frecuente que se articulen genuinos discursos públicos, ni proyectos comunes, ni espacios genuinos de solidaridad o colaboración, sino un trabajo narcisista de marketing pensado como una fábrica de simulacros sobre uno mismo. Las

${ }^{18}$ Foucault, M.: Estética, ética y hermenéutica. A. Gabilondo (introducción, traducción y edición). Paidós, Barcelona, Buenos Aires, México, 1999, p. 294. 
redes digitales se conforman como estructuras reticulares que en la práctica son finitas y en las que operan silenciosa y eficazmente una multitud de invisibles estrategias de censura y gramáticas idiosincráticas que, en la medida en que la red pretenda erigirse como dispositivo político a través de la transmisión del flujo de la información, debe confrontar el hecho de que se parece más a un modelo de control arterial como el denunciado por Adorno que a las supuestas horizontales y democráticas plataformas en las que conviven de manera ilimitada un conjunto indefinido de Weltanschauungen divergentes.

Los fenómenos de aceleración propiciados por el intercambio de información de las redes sociales comparten indudablemente una raíz en la que las consecuencias paradójicas de la libertad se extienden hasta sus propias contradicciones. Es en este sentido en el que por ejemplo Hartmut Rosa ha tratado de dar un renovado impulso a la teoría crítica, analizando las formas de temporalidad de la modernidad tardía a partir precisamente del reconocimiento de regímenes temporales invisibles y aparentemente despolitizados que determinan inflexiblemente los nuevos territorios conquistados por la libertad. La descripción de Rosa de estos regímenes temporales es claramente compatible con una visión tradicional de los procesos de secularización en los que la aceleración viene a ocupar el lugar de la promesa en una vida trascendente. ${ }^{19}$ Por su parte, el estudio recientemente publicado de Vicente Serrano Marín sobre Facebook pone el acento en otra de las formas en las que la aceleración, como rasgo característico de las sociedades modernas, se vincula a la torsión en la que la libertad gana su nueva forma de expresión haciendo coincidir en una misma identidad, por un lado las formas de producción, autonomía, capacidad de decisión o posesión de los medios de producción y por otro lado al sometimiento en sus múltiples formas ${ }^{20}$. Los procesos de subjetivación son ya, como recuerdan los análisis de Judith Butler sobre Freud, Althusser o Foucault, una instancia de doble valencia activa y pasiva: assujetissement. ${ }^{21}$ No sorprende en ese sentido que Serrano Marín identifique los modos de producción de identidad y afectividad que operan en el contexto de las redes sociales con la máquina de producción capitalista. Al margen de si la identificación entre la ideología subterránea de las redes sociales pueda reducirse a su fatal coincidencia con las leyes del capita-

${ }^{19}$ Rosa, H.: Alienación y aceleración. Hacia una teoría crítica de la temporalidad en la modernidad tardia, trad. de Centro de Investigaciones Interdisciplinarias en Ciencias Y Humanidades (CEIICH), revisión y notas de E. Dávila y M. Aguiluz Ibargüen, Universidad Nacional Autónoma, Katz, Madrid, 2016, p. 47.

${ }^{20}$ Serrano Marín, V.: Fraudebook. Lo que la red social hace con nuestras vidas, Plaza y Valdés, Madrid, 2016.

${ }^{21}$ Butler, J.: Mecanismos psíquicos del poder. Teorías sobre la sujeción, trad. de J. Cruz, Cátedra, Madrid, 2010. 
lismo, parece innegable que no se trata de una herramienta desprovista de decantaciones ideológicas. Ciertamente es un lugar idóneo para reproducir la clásica estructura autorreferencial o autopoiética del capitalismo en la medida en que se convierte en una máquina idónea para hacer del propio discurso anticapitalista una mercancía, pero la respuesta que se pretende sugerir aquí, tratará de circunscribirse a una valoración del concepto de transparencia en la línea de la propuesta de Gianni Vattimo o posteriormente y en un contexto teórico bien diferente, de Byung-Chul Han, sobre el papel de los mass media en el nacimiento de la sociedad postmoderna, que atienda también a los presupuestos ontológicos que tienen en su base. Frente al optimismo de Vattimo en La Sociedad de la Transparencia, y la parvedad teórica de Han, Lanceros nos advierte de los peligros del dogmatismo tecnológico, funcionalista y sistémico nutriendo su posición con los análisis de Marcuse sobre el hombre unidimensional, el discurso heideggeriano sobre la técnica o la teoría de sistemas luhmaniana. Por lo que respecta a la comprensión del concepto de sociedad de la transparencia empleado por Han, parece necesario precisar cómo su presentación del concepto de psicopolítica como superación del paradigma biopolítico foucaultiano, funciona como pórtico de tal concepción.

\section{UNA NOTA CRÍTICA AL CONCEPTO DE PSICOPOLÍTICA}

El biopoder como plexo de mecanismos legales, disciplinarios y securitarios a partir de los cuales determinados rasgos biológicos se constituyen en estrategias políticas capaces de trazar y desplazar las relaciones de poder inscritas silenciosamente en el control de los cuerpos parece en cierto sentido ajustarse bien a algunas de las determinaciones del paradigma inmunológico que la lógica de la psicopolítica pretende superar. Por ejemplo, la distancia que la razón monológica establece respecto de la locura o, en general, las prácticas de exclusión o normalización y regularización en el seno de lo disciplinario se avienen en principio adecuadamente a este paradigma. Pero, incluso en este caso, no conviene perder de vista el hecho de que, al contrario de lo que ocurre con la ley como reverso de lo ilegal, la norma no establece juegos binarios de exclusiones y oposiciones. ${ }^{22}$ Más bien la norma reasume y reduce toda diferencia en la medida en que se constituye por definición de manera vicaria respecto de su propia desviación. Es decir, la transgresión es la condición de posibilidad de la norma que, sólo en su movimiento regulativo y asintótico, puede desvelar un ideal. Lógicamente, la corrección es anterior a este ideal,

${ }^{22}$ Foucault, M.: Seguridad, territorio y población. Curso en el Collège de France (19771978), trad. de H. Pons, Akal, Madrid, 2008, pp. 74-75. 
la adecuación es anterior a la representación y la norma es ontológicamente posterior a su aplicación.

En este sentido cabría decir que Foucault es estrictamente kantiano: la norma no es exactamente una función abstracta y aplicable a hechos concretos dados de antemano y subsumibles, sino que la norma aparece tras el ejercicio de corrección de una desviación concreta. Y, constructivamente, la condición de posibilidad de la ejecución de las reglas es al mismo tiempo la condición de posibilidad de las reglas. Este movimiento explica la lógica interna propia de la economía de maximización de la visibilidad del poder disciplinario. Al no estar referida unívocamente a actos concretos, como la ley que se aplica implacablemente sobre hechos tipificados e identificables de antemano, sino precedida por una totalidad inagotable y pluralmente indefinida de posibilidades de desviación y corrección, la norma requiere la mirada escudriñadora que comparten lo disciplinario y las ciencias humanas en la modernidad:

En el panóptico proyectado por Bentham esta mirada adquiere, por así decir, forma arquitectónica. Esta misma estructura es la que hallamos en la cuna de las ciencias humanas. No es casualidad que estas ciencias, sobre todo la psicología clínica, pero también la pedagogía, la sociología, la politología, y la antropología cultural, puedan acomodarse sin excesivos problemas a la tecnología de poder que en las instituciones cerradas encuentra, por así decir, su expresión arquitectónica. Se transforman en terapias y en técnicas sociales, y constituyen el medio más efectivo del nuevo poder, del poder disciplinario que domina a la modernidad. Ello se debe a la circunstancia de que la penetrante mirada del científico social puede ocupar ese lugar central del panóptico, desde el que puede verse sin ser visto. ${ }^{23}$

Tomando como base la reflexión de Foucault sobre el panoptismo Han explicita, como se ha sugerido, los presupuestos de la psicopolítica como superación del paradigma del biopoder formulado por Foucault. A juicio de Han, la diferencia entre ambos diagnósticos se cifra en los siguientes postulados. La biopolítica subrayaría el elemento coactivo, frente a la psicopolítica, cuya patología consiste en sentido opuesto en la infinita posibilidad de hacer. La biopolítica funciona a través de oposiciones dialécticas; hay amigos y enemigos, conflicto de clases, resistencia de lo Otro, en definitiva, negatividad. La psicopolítica sin embargo se disuelve en una positividad sin resto donde el sujeto de la explotación es uno mismo. El biopoder es represor y genera sujetos sumisos. El psicopoder es permisivo, sobreproductivo, hiperatento, y produce sujetos dependientes. El biopoder se vincula a una óptica perspectivista y anamorfótica, con

${ }^{23}$ Habermas, J.: El discurso filosófico de la modernidad, M. Jiménez Redondo (trad.), Taurus, Madrid, 1989, p. 294. 
sus ángulos muertos, sus secretos, sus pliegues y veladuras, sus márgenes e impenetrabilidades, sus máscaras y ardides, sus ambigüedades y sus códigos de seducción, sus latencias, y sus juegos de refracciones. La psicopolítica es totalizadora, clara, homogénea: el conocimiento se extiende sin huecos ni lagunas. La proliferación de los discursos inmunológicos en la filosofía contemporánea moderna -las propuestas de Agamben y Esposito son claros exponentes- serían paradójicamente síntomas de su pérdida de eficacia. Como si en su propia verbalización y autoconciencia se certificase la pérdida de vigencia de la estrategia por la cual inoculamos una pequeña dosis del elemento extraño que nos amenaza para conjurar una amenaza mayor.

Que la explicación inmunológica no agote la complejidad de lo real no significa a nuestro juicio ni que el planteamiento foucaultiano no estuviera avisado de ello, ni que la propuesta psicopolítica de Han supere genuinamente dicho horizonte de comprensión proporcionando otro radicalmente nuevo. Más bien al contrario, a nuestro entender, en el Foucault de Vigilar y Castigar ya pueden anticiparse las herramientas conceptuales para dar este salto. La eficacia del poder disciplinario se juega precisamente en su inverificabilidad, su capilaridad y su carácter infinitesimal. El efecto del poder disciplinario en Foucault está ya desligado de su efectiva ejecución y su eficacia consiste precisamente en su silencio y sutilidad así como en la incorporación y complicidad del propio sujeto sometido:

El que está sometido a un campo de visibilidad, y lo sabe, reproduce por su cuenta las coacciones del poder; las hace jugar espontáneamente sobre sí mismo; inscribe en sí mismo la relación de poder en la cual juega simultáneamente los dos papeles; se convierte en el principio de su propio sometimiento. Por ello, el poder externo puede aligerar su peso físico; tiende a lo incorpóreo, y cuánto más se acerca a este límite, más constantes, profundos, adquiridos de una vez para siempre e incesantemente prolongados serán sus efectos: perpetua victoria que evita todo enfrentamiento físico y que siempre se juega de antemano. ${ }^{24}$

Por otra parte el ejercicio del poder no proviene del exterior, se trata de un poder democráticamente distribuido y controlado, el panóptico es un "edificio transparente" 25 una "jaula transparente" 26 que intensifica la producción y actúa "sin laguna ni interrupción"27. Para terminar Foucault afirma expresamente que no se trata de una disciplina meramente negativa, sino extensiva y positiva. No

\footnotetext{
${ }^{24}$ Foucault, M.: Vigilar y castigar. El nacimiento de la prisión. S. XXI, 1990, España, p. 206.

${ }^{25}$ Ibíd., 211.

${ }^{26}$ Ibíd., 212.

${ }^{27}$ Ibíd., 212.
} 
hay ejemplo más claro que el de la aparición omnipresente del teléfono móvil que no parece estar ya fuera de lugar en ningún contexto, cerrando por tanto el espacio para lo sagrado o separado. Transparencia, productividad, capilaridad, positividad, omnipresencia, ausencia de exterioridad. Todo aquello que Han presentaba como superación de la estructura del biopoder y que ya otros autores habían señalado con acierto como una propiedad propia de la modernidad como resultado de la Entzauberung weberiana, compartiendo por tanto la ambivalencia señalada a propósito del concepto de aceleración, parece estar presente en la propuesta foucaultiana con una expresiva resolución. ${ }^{28}$ Por lo que, en última instancia, la tesis de Han, sería evaluada a nuestro entender, en términos más justos si se presenta como una prolongación de las posiciones novedosas de Foucault o Marcuse, que como una efectiva superación.

Las ciencias humanas en la modernidad prolongan este efecto normalizadordisciplinario. Frente a la interdicción antipsicologista kantiana de resolver el plano de la validez desde lo genético, la genealogía foucaultiana mostrará cómo lo que se presenta como universal es en realidad contingente, esto es, que la verdad necesita como su condición la ocultación de la voluntad de verdad y que respecto de dicha voluntad de verdad ya no cabe preguntar por su condición de verdad o falsedad sino por sus estructuras de poder y por la génesis -histórica, institucional, contingente- de sus condiciones de validez. Si el artificio de la máquina política moderna era, según el célebre juicio de Rousseau, la autocoacción, lo característico de las formas contemporáneas de violencia radica precisamente, en continuidad con esta perspectiva, en la coincidencia entre ambas esferas, como mostraría la descripción de Han de las transformaciones topológicas de la violencia que se concretan en una interiorización de la violencia como seña de identidad de la modernidad, con su consiguiente retirada del escenario público y la sustitución de la lucha frontal por el modelo del contagio. El tipo de poder propio de las sociedades modernas no es por tanto el poder de muerte gestionado por el soberano, sino un poder productivo que tiene como fin invadir la vida en todos sus intersticios.

\section{CONCLUSIONES}

La lectura foucaultiana del texto de Kant sobre la Ilustración permite por tanto adelantar algunas conclusiones sobre los problemas ligados a las transformaciones de la experiencia temporal desde la Modernidad y sobre la enunciada paradoja de la aceleración. Las reflexiones de Heidegger sobre la Modernidad en La época de la imagen del mundo de las que el pensamiento de Han es clara-

28 "La experiencia del hombre moderno reposa en la ilusión de la transparencia": p. 96. 
mente deudor aportan asimismo una clave de interpretación muy útil para responder a nuestro problema. Heidegger nos había explicado que, frente a otras épocas de la historia definibles por proyectar una determinada imagen o $\mathrm{Wel}$ tanschauung del mundo ligada a ciertos presupuestos y horizontes de comprensión, la Modernidad no es una época entre las épocas a la que pueda hacerse corresponder una determinada imagen del mundo. La Modernidad es la época en la que se "suspende" el tiempo (precisamente esto quiere decir "época") para otorgar sentido a las otras épocas; es la época en la que el mundo mismo es representación o imagen. Si Kant decía que los signos de la historia funcionan en virtud de la lógica de la profecía que se cumple a sí misma y Heidegger que la modernidad era pensar-ver desde lo ya conocido-iluminado de antemano, Koselleck distingue entre la profecía y el pronóstico en los siguientes términos:

Mientras que la profecía traspasaba el horizonte de la experiencia calculable, el pronóstico se sabe vinculado a la situación política. Tan vinculado está que formular un pronóstico significa ya modificar la situación. El pronóstico es un momento conocido de acción política. Está referido a acontecimientos cuya novedad alumbra. ${ }^{29}$

El gobierno de la transparencia puede en este sentido ser concebido como una extensión de la lógica de la modernidad, como una consecuencia natural y exacerbada de ésta, donde la imaginación, lejos de lo que predicaba la mencionada doctrina kantiana del esquematismo trascendental, funciona sin la guía del concepto. Por tanto, la aceleración propia de nuestro tiempo, ese tiempo en fuga que hemos caracterizado como tiempo sin concepto y carente de narración correspondería a una forma de historia sin ejemplaridad, ni teleología, ni vocación de sistema. Sin embargo, el fenómeno de la aceleración en un sentido general, vinculado todavía a la escatología cristiana quedaba asimilada a la noción de progreso. Que la Ilustración, con su noción de progreso y sus metarrelatos emancipatorios pueda concebirse como una condición de posibilidad para el desarrollo del concepto general de aceleración, lo demuestra el hecho de que se considerara que ciertos pueblos estaban "más adelantados" que otros. Por su parte, la transparencia se convierte en el dispositivo más adecuado para la aceleración por su capacidad para suprimir la negatividad: las resistencias que estiran el tiempo lo ralentizan con sus sistemas de jerarquías y valores que roturan y cortan el devenir otorgándole una dirección, una consistencia y hasta una duración.

Foucault subraya que la divisa de la Ilustración desplaza e invierte la relación entre la voluntad, la razón y la autoridad porque la mejor garantía de obediencia a la autoridad es precisamente la autonomía y la autocoacción, lo que

${ }^{29}$ Koselleck, R.: op. cit. p. 32-33. 
Rousseau describía como el artificio político de la máquina moderna. En este sentido no es casual que la época de la autocoacción o la coincidencia entre el poder disciplinario y su contrafigura, a saber, la libertad, sea la época del iluminismo donde aceleración significa acortamiento del espacio necesario para arribar a un determinado fin que escande con su luz ese recorrido. Frente a la aceleración centrípeta propia de la postmodernidad en la que la iluminación es tan total y la transparencia tan perfecta que muestra cada cosa sin resto a su través, entregando todo a la claridad porque no hay ningún foco de retracción oculto que oriente el sentido de lo que aparece, el vínculo entre la luz y el pliegue, entre poder o coacción y libertad propio de la aceleración centrífuga responde a la misma estructura metafísica con la que Heidegger había caracterizado las líneas fundamentales del pensamiento moderno, aquél que sólo aprende lo ya conocido de antemano ${ }^{30}$ o que ve aquello previamente iluminado o anticipado por la razón; esa estrategia por la que la metafísica platónica se adentró en la historia del olvido del ser con la imposición del paradigma de la verdad como orthótes o corrección de la mirada ${ }^{31}$ y que podemos reconocer también en la herencia kantiana de la fenomenología de Lambert: el conocimiento funciona como una óptica trascendental que, para erigir un sistema $a$ priori de la razón pura, calibra los fenómenos con el fin de arrojar claridad allí donde las apariencias han dejado a la realidad opaca tomando como objeto la luz de la propia razón entendida como un instrumento del conocer. ${ }^{32}$

¿Qué es la Ilustración? (...) Esto lo sabe todo aquel que mediante un par de ojos ha aprendido a reconocer dónde reside la diferencia entre claro y oscuro, entre luz y tinieblas. (...) ¿Sobre qué objetos se puede y se debe extender la Ilustración? (...) ¿Sobre qué sino sobre todos los objetos visibles? (...) La Ilustración, es decir, tanto conocimiento como sea necesario para poder distinguir, siempre y en todo lugar, lo verdadero de lo falso, debe, por eso, extenderse sin excepción sobre todos los objetos sobre los que pueda extenderse, es decir, sobre todo lo visible a nuestros ojos externos e internos. (...) ¿A través de qué medidas seguras se la fomenta? (...) multiplicar las luces, apartar los cuerpos opa$\cos (\ldots)$, iluminar cuidadosamente todos los rincones y cavidades." 33

${ }^{30}$ Heidegger: La pregunta por la cosa. La doctrina kantiana de los principios trascendentales, trad. de E. G. Belsunce y Z. Szankay, Orbis, Barcelona, 1985.

${ }^{31}$ Heidegger, M.: "La doctrina platónica de la verdad" en Hitos, trad. de H. Cortés y A. Leyte, Alianza, Madrid, 2000.

${ }^{32}$ Lambert, J. H.: Neues Organon oder Gedanken über die Erforschung und Bezeichnung des Wahren und dessen Unterscheidung vom Irrtum und Schein, Leipzig, 1764.

${ }^{33}$ Wieland, Ch. M.: "Seis preguntas sobre la Ilustración” en ¿Qué es la Ilustración? trad. de A. Maestre y J. Romagosa, Tecnos, Madrid, 1998, pp. 45-51. 


\section{BIBLIOGRAFÍA}

Baudrillard, J.: El crimen perfecto, trad. de Joaquín Jordá, Anagrama, Barcelona, 2000.

Bürger, P. y Bürger, Ch.: La desaparición del sujeto: una historia de la subjetividad de Montaigne a Blanchot, trad. de A. González Ruiz, Akal, 2001.

Butler, J.: Mecanismos psíquicos del poder. Teorías sobre la sujeción, trad. de J. Cruz, Cátedra, Madrid, 2010.

Deleuze, Kant y el tiempo, trad. de Equipo Editorial Cactus, Cactus, Buenos Aires, 2008.

Foucault, M.: Las palabras y las cosas, una arqueología de las ciencias humanas, trad. de E. C. Frost, S. XXI, España, 1988.

Foucault, M.: Estética, ética y hermenéutica. A. Gabilondo (introducción, traducción y edición). Paidós, Barcelona, Buenos Aires, México, 1999.

Foucault, M.: Vigilar y castigar. El nacimiento de la prisión. S. XXI, 1990, España.

Foucault, M.: Seguridad, territorio y población. Curso en el Collège de France (19771978), trad. de H. Pons, Akal, Madrid, 2008.

Foucault, M.: Kant, I. Anthropologie d'un point de vue pragmatique. Précédé de Introduction à l'anthropologie. Librairie Philosophique J. Vrin, Paris, 2008.

Fukuyama, F.: El fin de la historia y el último hombre, trad. de P. Elías, Planeta, Barcelona, 1992.

Habermas, J.: El discurso filosófico de la modernidad, M. Jiménez Redondo (trad.), Taurus, Madrid, 1989.

Han, Byung-Chul: La pregunta por la cosa. La doctrina kantiana de los principios trascendentales, trad. de E. G. Belsunce y Z. Szankay, Orbis, Barcelona, 1985.

Han, Byung-Chul: "La doctrina platónica de la verdad" en Hitos, trad. de H. Cortés y A. Leyte, Alianza, Madrid, 2000.

Han, Byung-Chul: Prolegómenos para una historia del concepto de tiempo, trad. de J. Aspiunza, Alianza, Madrid, 2006.

Han, Byung-Chul: La sociedad de la transparencia, Barcelona, Herder, 2013.

Han, Byung-Chul: Psicopolítica. Neoliberalismo y nuevas técnicas de poder, Barcelona, Herder, 2014. Heidegger:

Jameson, F.: "The end of Temporality" en: Critical Inquiry, The University of Chicago Press, Vol. 29, nº4, pp. 695-718.

Jameson, F. y Sánchez Usanos, D.: Reflexiones sobre la postmodernidad. Una conversación de F. Jameson con D. Sánchez Usanos, Abada, Madrid, 2012.

Koselleck, R.: Aceleración, prognosis y secularización, trad. introducción y notas de F. Oncina, Pre-textos, Valencia, 2003. 
Lambert, J. H.: Neues Organon oder Gedanken über die Erforschung und Bezeichnung des Wahren und dessen Unterscheidung vom Irrtum und Schein, Leipzig, 1764.

Lanceros, P.: La modernidad cansada y otras fatigas, Biblioteca Nueva, Madrid, 2006.

Lyotard, J.-F.: La condición postmoderna. Informe sobre el saber, trad. de M. Antolín Rato, Cátedra, Madrid, 1987.

Ricoeur P.: Tiempo y narración I. Configuración del tiempo en el relato histórico, trad. de A. Neira, S.XXI Editores, Argentina.

Rosa, H.: Alienación y aceleración. Hacia una teoría crítica de la temporalidad en la modernidad tardia, trad. de Centro de Investigaciones Interdisciplinarias en Ciencias y Humanidades (CEIICH), revisión y notas de E. Dávila y M. Aguiluz Ibargüen, Universidad Nacional Autónoma, Katz, Madrid, 2016.

Rousseau: El contrato social o principios de derecho político, Tecnos, María José Villaverde (ed.), Madrid, 2016.

Serrano Marín, V.: Fraudebook. Lo que la red social hace con nuestras vidas, Plaza y Valdés, Madrid, 2016.

Vattimo, G.: La sociedad de la transparencia, trad. e introducción de Teresa Oñate, Paidós, Barcelona, 1990. 